\title{
Sinigrin Act as A Therapeutic Agent in Lung Carcinoma H460 Cell Line
}

\section{Nishita Gogia ${ }^{1}$, Rajendiran Selvam, Kasturi Revathi*}

1. Guru Nanak College Velachery, Chennai, 600042, Tamilnadu, India.

2. CENTRAL Research Laboratory, Meenakshi Academy of Higher Education and Research, Chennai-78, Tamilnadu, India.

*Corresponding author's E-mail: arselvaam@gmail.com

Received: 13-07-2020; Revised: 25-09-2020; Accepted: 04-10-2020; Published on: 20-10-2020.

\section{ABSTRACT}

Cancer is one of the foremost causes of death in the United States and around the world. The beginning of contemporary drugtargeted therapies has patently improved cancer patients' care. However, advanced metastasized cancer remains untreatable. Hence, continued searching for safer and more effective chemoprevention and treatment is needed for the improvement of the efficiency and to lower the treatment cost for cancer care. A phytochemical compound with cancer chemoprevention is an emerging strategy to avoid, block, delay, or cure cancer. Lung tumor is the most common cause of cancer death in men and the second most common in women after breast cancer. Sinigrin is a glucosinolate compound in the Brassicaceae family. The therapeutic benefits and the anticancer activity of sinigrin in cancer cell lines were carried out. Free radical scavenging assays, Antioxidant Assays, LDH, cell viability and morphology of lung adenocarcinoma $\mathrm{H} 460$ was carried out. Current research has been employed in a cell line model ( $\mathrm{H} 460)$ to systematically study the efficacy of Sinigrin in the anticancer activity.

Keywords: Chemoprevention, sinigrin, anti-cancer, antioxidant assays, lung adenocarcinoma.

QUICK RESPONSE CODE $\rightarrow$

DOI:

10.47583/ijpsrr.2020.v64i02.025

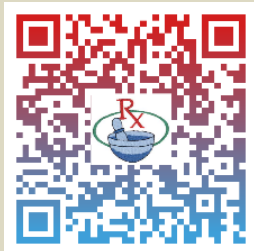

DOI link: $\underline{\text { http://dx.doi.org/10.47583/iipsrr.2020.v64i02.025 }}$

\section{INTRODUCTION}

ung carcinoma is a malignant lung tumor considered by uncontrolled cell growth in the lung tissues of cells lining air passages. The two main types are small-cell lung cancer and non-small-cell lung cancer. The most common symptoms are coughing, shortness of breath and chest pains. Worldwide lung cancer is the most common cancer among men in terms of both incidence and mortality and among women is the third highest incidence, and is second after breast cancer mortality ${ }^{1}$. Cancer develops genetic damage to DNA and epigenetic changes. These changes affect the normal functions of the cell, including cell proliferation, programmed cell death (apoptosis) and DNA repair. As more damage accumulates, the risk of cancer increases ${ }^{2}$. Natural plants have been used to prevent and to treat various diseases for thousands of years. There are excellent sources of bioactive components exerting their health beneficial effects, and very often, these sources are materials for gourmet food consumption. Certain bioactive components from the plants have been confirmed for their anti-cancer activities. Chemoprevention is defined as the use of pharmacologic or natural compounds to prevent tumor development, promotion, or progression ${ }^{3}$.
Sinigrin is a chief glucosinolate, related to Brassicaceae families, such as the seeds of black mustard, brussels sprouts, and broccoli. It has been conveyed that Brassicaceae juncea (Indian mustard) contains major amounts of sinigrin ${ }^{4}$. Sinigrin has shown antibacterial, antifungal, antioxidant, anti-inflammatory, wound healing properties. However, the clear-cut details of the pharmacological activity of sinigrin in lung cancer cell line (H460) are not currently available. Therefore, in the present study, it has been employed as a cell line model to systematically study the efficacy of Sinigrin in the anticancer activity.

\section{MATERIALS AND METHODS}

\section{Lung Cancer (H460) cell line}

Lung cancer cell line (H460) cell line was procured from NCCS, Pune and maintained in Dulbecco's minimal essential medium (DMEM) with 10\% FBS, and antibiotic mixture (Penicillin, streptomycin and ampicillin 100 units/ $\mathrm{mL}$ ) under defined conditions of temperature at $37^{\circ} \mathrm{C}, 95 \%$ humidity and $5 \% \mathrm{CO} 2$.

\section{Cell viability assay}

The cytotoxic activity of the Sinigrin was determined using the 3-(4,5-dimethylthiazol-2-yl)-2,5- diphenyltetrazolium bromide ${ }^{5}$. Sinigrin concentrations were prepared in the range of $100-20 \mu \mathrm{g} / \mathrm{mL}$ from the stock solution by serial dilution using Dimethyl sulphoxide (DMSO). Lung cancer cell line (H460) was trypsinised and the cells were counted using haemocytometer following standard procedure. $100 \mu \mathrm{l}$ of the lung cancer cell line at $1 \times 104$ cells $/ \mathrm{mL}$ was added to poly L-lysine coated 96 well plate and incubated at $37^{\circ} \mathrm{C}$ in a humidified $5 \% \mathrm{CO} 2$ incubator. After 24 hours 
of incubation, the old medium was replaced with fresh medium and $50 \mu \mathrm{L}$ of the sinigrin was added and incubated for 48 hours at $37^{\circ} \mathrm{C}$ in a humidified $5 \% \mathrm{CO} 2$ incubator. $30 \mu \mathrm{l}$ of $0.5 \% \mathrm{w} / \mathrm{v}$ MTT was added and incubated at room temperature for 4 hours. After incubation, $50 \mu \mathrm{L}$ of acidisopropanol was added to dissolve the formazan formed and incubated at room temperature for 30 minutes. Then absorbance was taken at 554nm using Bio-Rad micro-titer plate reader. The assay was performed in triplicates.

\section{Free Radical Scavenging Assays}

\section{DPPH Radical Scavenging Assay}

The free radical scavenging capacity of Sinigrin was determined using $\mathrm{DPPH}^{6}$. DPPH $(200 \mu \mathrm{M})$ solution was prepared in $95 \%$ methanol. From the stock Sinigrin solution $20-100 \mu \mathrm{g} / \mathrm{ml}$ were taken in five test tubes. $0.5 \mathrm{ml}$ of freshly prepared DPPH solution was incubated with test drug and after 10 minutes, absorbance was taken as 517 $\mathrm{nm}$ using spectrophotometer. Standard ascorbic acid was used as reference.

\section{ABTS Assay}

ABTS radical scavenging activity of Sinigrin was determined according to the method of Re et al., 19997. Briefly, ABTS radical cation $(\mathrm{ABTS} \bullet+)$ was produced by mixing $A B T S$ stock solution (7 $\mathrm{mM}$ in water) with $2.45 \mathrm{mM}$ potassium persulfate and allowing the mixture to stand in the dark at room temperature for $12-16 \mathrm{~h}$ before use. Then, ABTS $\bullet+$ solution was diluted with ethanol to an absorbance of 0.7 at $734 \mathrm{~nm}$. To $3.0 \mathrm{ml}$ of diluted ABTS $\bullet+$ solution, different concentration $(20-100 \mu \mathrm{g} / \mathrm{ml})$ of Sinigrin in ethanol was added and after $1 \mathrm{~min}$, the decrease in absorbance was measured at $734 \mathrm{~nm}$ spectrophotometerically.

\section{Antioxidant Assays}

An activity of Superoxide dismutase was determined by the method of Marklund and Marklund ${ }^{8}, 1974$. The activity of catalase was assayed by the method of $\mathrm{Aebi}^{9}(1984)$. The amounts of reduced glutathione (GSH) in the samples were estimated by the method of Boyne and Ellman ${ }^{10}(1972)$.

\section{Lactate dehydrogenase Assay}

Lactate dehydrogenase (LDH) activity in the cell medium was determined using an LDH Kit (Pointe Scientific, Lincoln Park, MI, USA).

\section{Experimental protocol}

Based on MTT assay, the doses $75 \mu \mathrm{M}$ and $30 \mu \mathrm{M}$ of Sinigrin were selected for further studies.

Group 1: Control H460 cells treated with 0.1\% DMSO.

Group 2: $\mathrm{H} 460$ cells treated with $30 \& 75 \mu \mathrm{M}$ of Sinigrin for 24 hours.

\section{Statistical analysis}

The statistical package SPSS (Statistical Package for Social Science), version 10.0 for windows are used for statistical analysis. Results are expressed as mean \pm SD. Multiple comparisons of the significant ANOVA were performed by Duncan's multiple comparison tests. A $p$-value of $<0.05$ was considered as statistically significant.

\section{RESULTS}

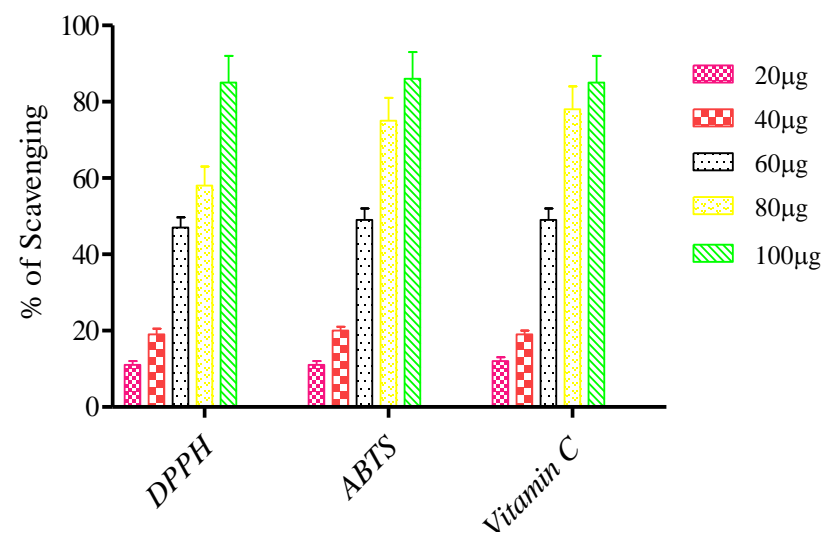

Figure 1: Shows the DPPH and ABTS scavenging potential in Sinigrin.

Figure 1 shows the DPPH and ABTS scavenging potential in sinigrin. At a concentration of $100 \mu \mathrm{g} / \mathrm{ml}$, the sinigrin significantly scavenged $79.31 \%$ of DPPH radicals and 77.55 $\%$ ABTS radicals.

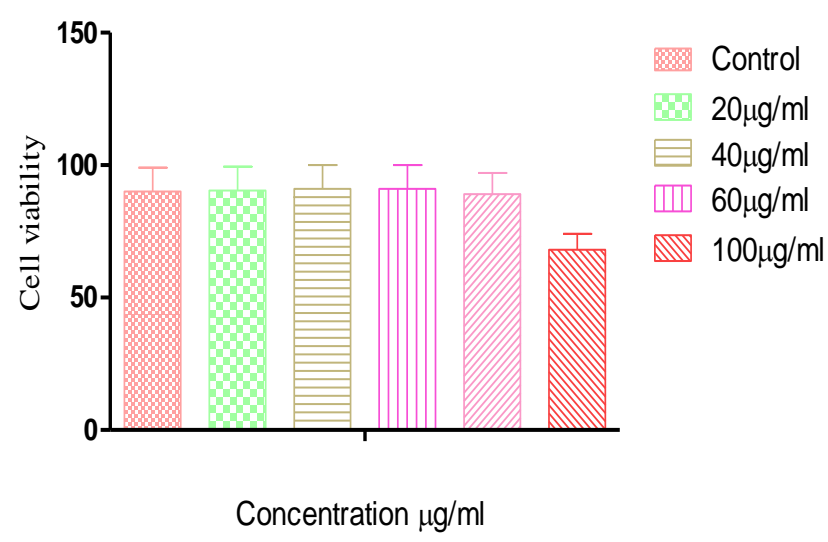

Figure 2: Depicts the cytotoxic effect of sinigrin on $\mathrm{H} 460$ cells in MTT assay.

Figure 2 shows a cytotoxic effect of Sinigrin on $\mathrm{H} 460$ cells in MTT assay. The $\mathrm{H} 460$ cells were treated with increasing concentrations of Sinigrin for 48 hours. The cell viability was measured in six-replicate using MTT assay.

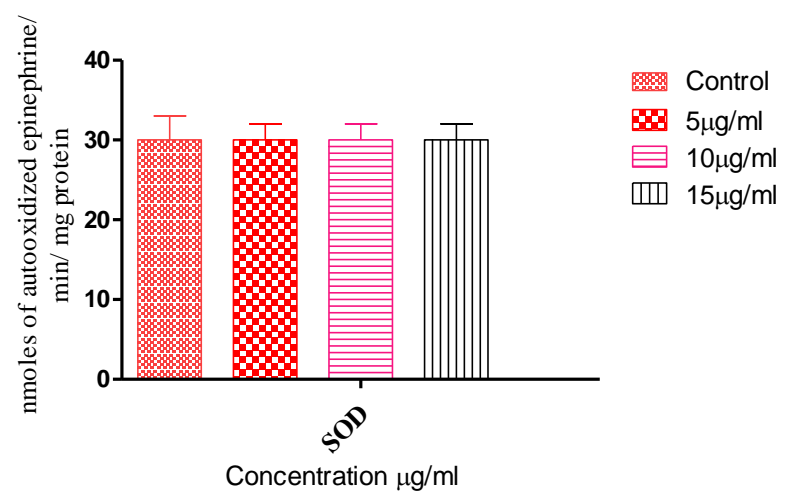

Figure 3: Status of superoxide dismutase (SOD) activities in H460 cells 
Figure 3 shows the status of SOD activity content in $\mathrm{H} 460$ and without Sinigrin. Data are presented as mean \pm SD (triplicate wells). A change in SOD activity was not significant in cell lines at all concentrations of sinigrin when compared to untreated cultures.

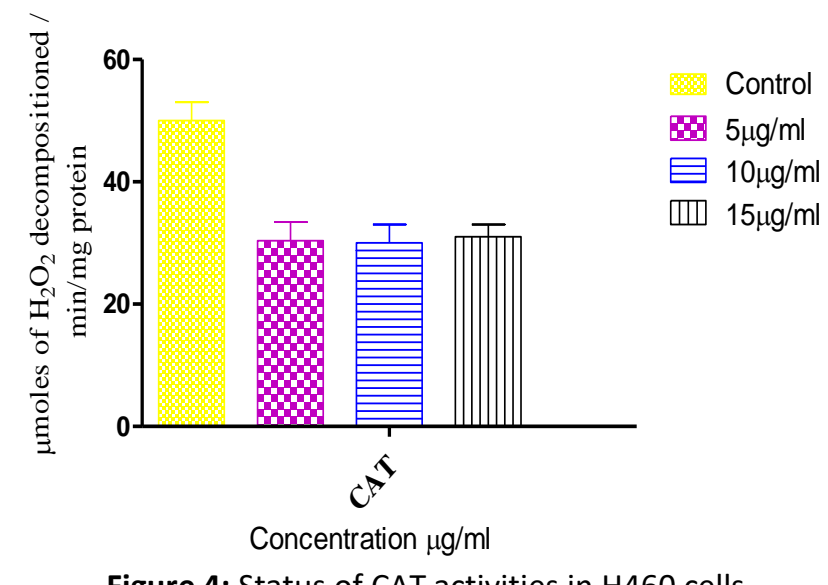

Figure 4: Status of CAT activities in $\mathrm{H} 460$ cells

Figure 4 shows the status of CAT activity content in H460 and without Sinigrin. Data are presented as mean \pm SD (triplicate wells). A change in CAT activity was not significant in cell lines at all concentrations of Sinigrin when compared to untreated cultures.

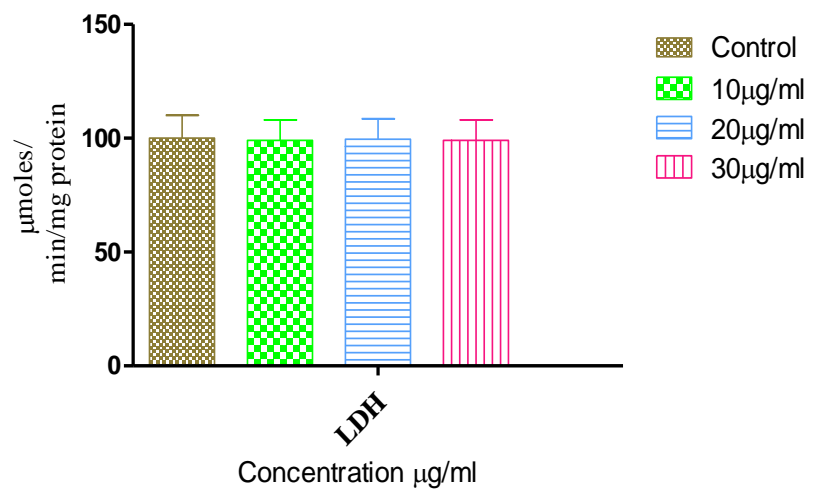

Figure 5: Effect of LDH activities in $\mathrm{H} 460$ cells

Figure 5 shows the status of LDH activity content in $\mathrm{H} 460$ and without Sinigrin. Data are presented as mean \pm SD (triplicate wells). A change in $\mathrm{LDH}$ activity was not significant in cell lines at all concentrations of Sinigrin when compared to untreated cultures.

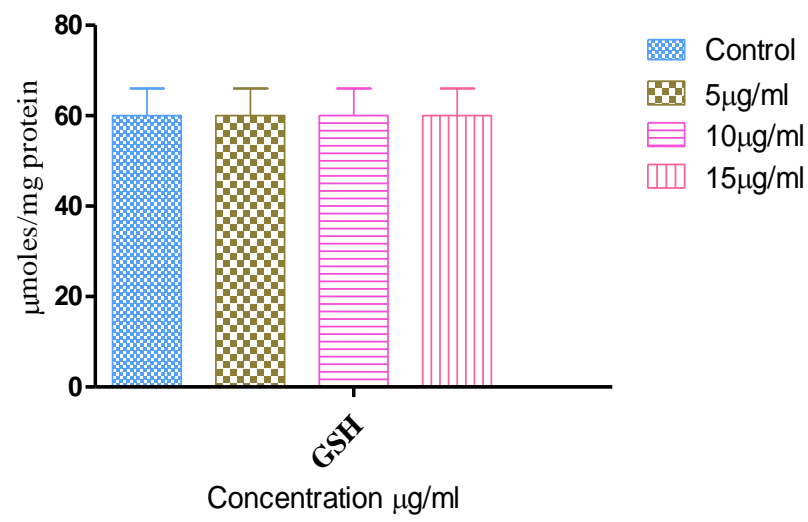

Figure 6: Effect of GSH activities in $\mathrm{H} 460$ cells
Figure 6 shows the status of GSH content in $\mathrm{H} 460$ and without Sinigrin. Data are presented as mean \pm SD (triplicate wells). A change in GSH activity was not significant in cell lines at all concentrations of Sinigrin when compared to untreated cultures.

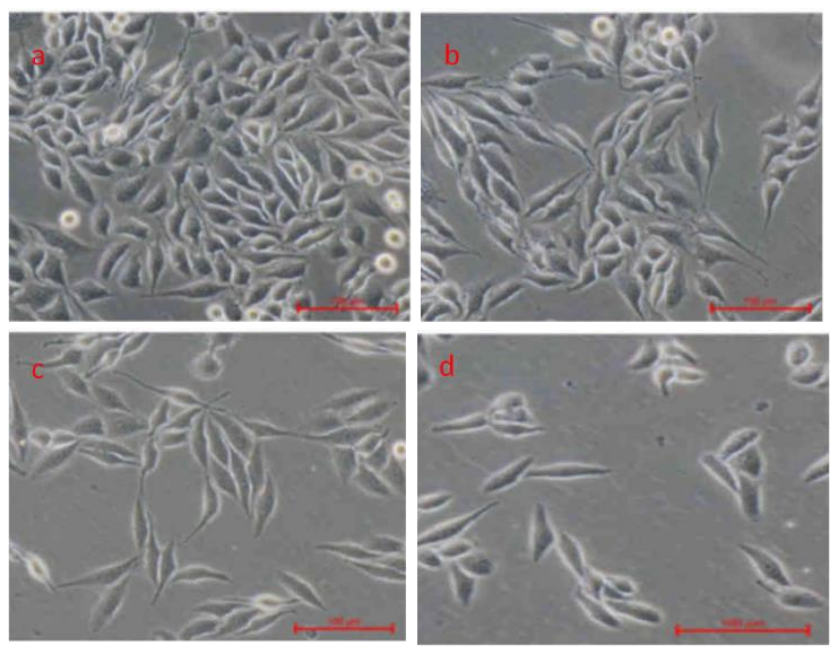

Figure 7: Morphological changes of lung adenocarcinoma H460 cell line.

Figure 7 shows the Morphology of lung adenocarcinoma H460 cells under inverted phase contrast microscopy. Morphologically, different dose $(5-15 \mu \mathrm{g})$ of sinigrin administration induced cell rounding and growth inhibition, which appeared to be dose- time dependent.

\section{DISCUSSION}

The goal of the present research was to evaluate the in vitro cytotoxic activity of sinigrin on $\mathrm{H} 460$ cells from human lungs cancer. Chemotherapy, radiation therapy, and surgery have been used for cancer treatment as a standard. However, these therapies have not been fully effective and the side effects are of concern. Due to the chemotherapy normal cells are affected and immune system became week. Hence, continued searching for safer and more effective chemoprevention and treatment is needed for the improvement of the efficiency and to lower the treatment cost for cancer care. Medicinal plants are the reservoirs of ecologically derived secondary metabolites and it gained extensive attention in recent years due to their physiological functions including free radical scavenging, antidiabetic, anticarcinogenic and antiinflammatory effects ${ }^{11}$.

DPPH and ABTS radical assays have been widely used as reliable methods for determining the free radical scavenging efficacy of the lead molecules. The principle of the DPPH free radical scavenging activity assay is based on the reduction of DPPH radicals in methanolic solution. Due to the presence of an odd electron, DPPH gives a strong absorption maximum at $515 \mathrm{~nm}$. It is generally accepted that substances which are able to donate hydrogen or an electron to DPPH, a synthetic nitrogen-centered stable radical, can be considered as antioxidants and therefore free radical scavengers. Sinigrin exhibited a maximum of 
79.31\% DPPH radical scavenging activity at a concentration of $100 \mu \mathrm{g} / \mathrm{ml}^{6}$.

$A B T S$ radicals are more reactive than DPPH radicals and the reaction with $A B T S$ radicals involve a single electron transfer process. It is applicable for both hydrophilic and lipophilic compounds ${ }^{7}$. ABTS radical assay is the preformed radical monocation of ABTS radical which is generated by oxidation of ABTS radicals with potassium persulfate and is reduced in the presence of such hydrogen-donating antioxidants. The antioxidant activity of different lead molecules depends on the number and location of hydroxyl and other functional groups such as carboxyl and phenolic ring system. Sinigrin exhibited a maximum of $77.55 \%$ ABTS radical scavenging activity at a concentration of $100 \mu \mathrm{g} / \mathrm{ml}$.

Cytotoxicity is seen predominantly as the potential of a compound to induce cell death. The in vitro cytotoxicity assays are widely used for chemicals screening for predicting toxicity in animals or Human ${ }^{12}$. Consequently, MTT was performed to evaluate cytotoxic effect of sinigrin on $\mathrm{H} 460$ lines. More closely, this cell line model allows the study of presystemic xenobiotic metabolism. The result obtained show that the sinigrin on $\mathrm{H} 460$ cells in MTT cytotoxic test. The strongest cytotoxic effect of sinigrin was observed on $\mathrm{H} 460$ cells. MTT showed the $50 \%$ inhibitory concentrations (IC50) of $60 \mu \mathrm{g} / \mathrm{mL}$. MTT assay clearly show that sinigrin causes cytotoxicity by altering the mitochondrial metabolism through succinate dehydrogenase activities whereas neutral red assay show alteration of cells membranes and transport causing an apparent decrease in cell viability. These results are consistent and paralleled with the morphological change and cells observed under inverted microscope and interpreted as cell death. The IC50 obtained in our study on $\mathrm{H} 460$ using MTT method is $60 \mu \mathrm{g} / \mathrm{ml}$ meaning that the sinigrin has potential anticancer properties.

Earlier reported ${ }^{13,14}$ has shown the anti- tumor effect of sinigrin by inhibiting proliferation and inducing apoptosis in human hepatoma cell line. In an attempt to elucidate the baseline levels of antioxidant enzyme status in $\mathrm{H} 460$ cell line, we measured the activities of SOD, CAT, and GSH and $\mathrm{LDH}$ contents. It has been highly suggested that in the process of carcinogenesis excessive accumulation of reactive oxygen species may play an important role in causing oxidative damage. In an attempt to defend the situation, antioxidant enzymes (SOD, GPx and CAT) may be elevated or reduced in these cells ${ }^{15}$. This study showed that SOD activity was higher in $\mathrm{H} 460$ cells by 2 fold compared to control, which may reflect the higher superoxide radicals in the former. However, we noted that other antioxidant enzymes CAT and GSH activities in $\mathrm{H} 460$ cell line were not significantly different when compared to normal cell line.

ROS are classified as endogenous carcinogen that induced cell mutation. The balance between the amount of oxidants and antioxidants will affect the cancer cell number. Oxidants will be converted by antioxidants into another oxidant compounds or neutral compounds. Radical superoxides will be converted by SOD to hydrogen peroxide, which will then be converted by CAT into water. Hydrogen peroxide will be converted into hydroxyl radicals when there is iron and low concentration of CAT. The hydroxyl radical is more reactive than the other oxidants. This hydroxyl radical will react with fat; resulting in the process of lipid peroxidation it will cause membrane damage ${ }^{16-19}$. In the $\mathrm{H} 460$ cell line, based on the research by Kattan et $\mathrm{al}^{20}$, there was a lower activity of SOD compared to the other breast cancer cell lines. However, in this study there was an increase in SOD activity, both convert radical superoxides into hydrogen peroxide. But the CAT activity in this cell line did not change significantly with the increase of time observation. Based on statistical analysis, the compounds that affect the cancer cells number are radical superoxides.

\section{CONCLUSION}

Based on this belief, combinations of the anticancer phytochemicals may have more effect and yield more potent therapeutic agents for cancer.The present investigation revealed that sinigrin can act as a potential alternative remedy for lung carcinoma. Further investigation is undertaken to identify the active compound behind the cytotoxic activity of the sinigrin.

\section{REFERENCES}

1. Davies G. Time Tables of Medicine. Black Dog \& Leventhal; New York: 2000

2. Laird PW. Cancer epigenetics. Hum Mol Genet, 14,1, 2005, R65-76.

3. Gutheil WG, Reed G, Ray A, Anant S, Dhar A. Crocetin: an agent derived from saffron for prevention and therapy for cancer. Curr Pharm Biotechnol, 13(1), 2012, 173-9.

4. Iqbal J, Abbasi BA, Ahmad R, et al. Potential phytochemicals in the fight against skin cancer: Current landscape and future perspectives. Biomed Pharmacother, 109, 2019, 1381-1393.

5. Freimoser FM, Jakob CA, Aebi M, Tuor U. The MTT [3-(4,5dimethylthiazol-2-yl)-2,5-diphenyltetrazolium bromide] assay is a fast and reliable method for colorimetric determination of fungal cell densities. Appl Environ Microbiol, 65(8), 1999, 3727-9.

6. Brand-Williams W, Cuvelier ME, Berset C. Use of a freeradical method to evaluate antioxidant activity. Food Sci Technol-Leb, 28, 1995, 25-30.

7. Re R, Pellegrini N, Proteggente A, Pannala A, Yang M, RiceEvans $C$, Antioxidant activity applying an improved ABTS radical cation decolorization assay, Free Radic Biol Med, 26, (9-10), 1999, 1231-1237

8. Marklund S, Marklund G. Involvement of the superoxide anion radical in the autoxidation of pyrogallol and a convenient assay for superoxide dismutase. Eur J Biochem, 47(3), 1974, 469-74.

9. Aebi H. Catalase in vitro. Methods Enzymo, 105, 1984, 121126. 
10. Boyne AF. Ellman GL. A methodology for analysis of tissue sulfhydryl components. Anal. Biochem, 46(2), 1972, 639-53.

11. Manthey JA, Biological properties of flavonoids pertaining to inflammation. Microcirculation, 7 (1), 2000, S29-S34.

12. Eisenbrand G, Pool-Zobel B, Baker V, Balls M, Blaauboer BJ, Boobis A, Carere A, Kevekordes S, Lhuguenot JC, Pieters R, Kleiner J. Methods of in vitro toxicology. Food Chem Toxicol., 40 (2-3), 2002, 193-236.

13. Kang HS, Kim KR, Jun EM, Park SH, Lee TS, Suh JW, et al. Cyathuscavins $A, B$, and $C$, new free radical scavengers with DNA protection activity from the Basidiomycete Cyathusstercoreus, Bioorg Med Chem Lett, 2008, 4047-50.

14. Lü JM, Lin PH, Yao Q, Chen C, Chemical and molecular mechanisms of antioxidants: Experimental approaches and model systems, J Cell Mol Med, 2010, 840-60.

15. Yunfeng Li; Changjiang Guo; Jijun Yang; Jingyu Wei; Jing Xu. and Shuang Cheng. Evaluation of antioxidant properties of pomegranate peel extract in comparison with pomegranate pulp extract. Food Chemistry, 96, 2006, 254-260.
16. Anderson, D.Antioxidant defences against reactive oxygen species causing genetic and other damage. Mutation Research/Fundamental and Molecular Mechanisms of Mutagenesis, 350(1), 1996, 103-108.

17. Blake, D.R., Allen, R.E. and Lunec, J. Free radicals in biological systems - a review orientated to inflammatory processes. British medical bulletin, 43(2), 1987, 371-385.

18. Girotti AW. Mechanisms of lipid peroxidation. Journal of free radicals in biology \& medicine. 1(2), 1985, 87-95.

19. James Melrose. The Glucosinolates, A Sulphur Glucoside Family of Mustard Anti-Tumour and Antimicrobial Phytochemicals of Potential Therapeutic Application. Biomedicines, 7, 2019, 62.

20. Kattan Z, Minig V, Leroy P, Dauça M, Becuwe P. Role of manganese superoxide dismutase on growth and invasive properties of human estrogen-independent breast cancer cells. Breast cancer research and treatment. 108(2), 2008, 203-15.

Source of Support: None declared.

Conflict of Interest: None declared.

For any question relates to this article, please reach us at: editor@globalresearchonline.net New manuscripts for publication can be submitted at: submit@globalresearchonline.net and submit_ijpsrr@rediffmail.com 